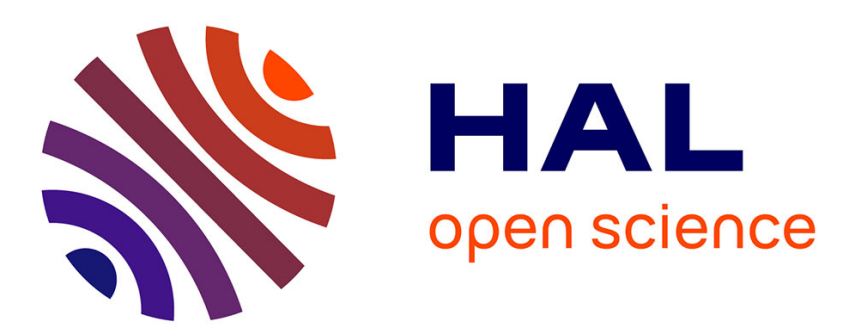

\title{
High quality factor of AlN microdisks embedding GaN quantum dots
}

\author{
Meletios Mexis, Sylvain Sergent, Thierry Guillet, Christelle Brimont, Thierry \\ Bretagnon, Bernard Gil, Fabrice Semond, Mathieu Leroux, Delphine Néel, \\ Sylvain David, et al.
}

\section{To cite this version:}

Meletios Mexis, Sylvain Sergent, Thierry Guillet, Christelle Brimont, Thierry Bretagnon, et al.. High quality factor of AlN microdisks embedding GaN quantum dots. International Workshop on Nitride Semiconductors (IWN2010), Sep 2010, Tampa, United States. pp.2328-2330, 10.1002/pssc.201001161 . hal-00633272

\section{HAL Id: hal-00633272 https://hal.science/hal-00633272}

Submitted on 18 Oct 2011

HAL is a multi-disciplinary open access archive for the deposit and dissemination of scientific research documents, whether they are published or not. The documents may come from teaching and research institutions in France or abroad, or from public or private research centers.
L'archive ouverte pluridisciplinaire HAL, est destinée au dépôt et à la diffusion de documents scientifiques de niveau recherche, publiés ou non, émanant des établissements d'enseignement et de recherche français ou étrangers, des laboratoires publics ou privés. 


\title{
High Quality Factor of AINMicrodisks Embedding GaN Quantum Dots
}

\author{
M. Mexis ${ }^{*}, 1$, S. Sergent ${ }^{2,3}$, T. Guillet ${ }^{* * 1}$, C. Brimont ${ }^{1}$, T. Bretagnon ${ }^{1}$, B. Gil ${ }^{1}$, F. Semond ${ }^{2}$, M. Leroux ${ }^{2}$, D. \\ Néel $^{4}$, S. David ${ }^{4}$, X. Chécoury ${ }^{4}$, P. Boucaud ${ }^{4}$ \\ ${ }^{1}$ GES, Université des Sciences et Techniques du Languedoc, Place Eugène Bataillon, 34095, Montpellier, France \\ ${ }^{2}$ CHREA-CNRS, 06560, Valbonne, France \\ ${ }^{3}$ Université de Nice Sophia Antipolis, Parc Valrose, 06102, Nice, France \\ ${ }^{4}$ Institut d'Electronique Fondamentale, CNRS - Université Paris Sud, 91405, Orsay, France
}

Received ZZZ, revised ZZZ, accepted ZZZ

Published online ZZZ(Dates will be provided by the publisher.)

PACS78.55.Cr, 78.67.Hc

* M.Mexis: meletios.mexis@univ-montp2.fr,Phone: +33467 143 775, Fax: +33467143 760
** T. Guillet:thierry.guillet@univ-montp2.fr, Phone: +33467 143 789, Fax: +33467143760

We report the observation of high quality (Q) factor whispering gallery modes for GaN/AlN quantum dot based microdisks. Room temperature photoluminescence measurements show a large number of high Q modes on the whole PL spectral range. For the first time we report Q values up to 6000 for nitride based cavities. We attribute this improvement of the $Q$ factor to the etching quality and to the relatively low cavity loss by inserting dots into the microdisks. The uniformity of the resonant modes with respect to a wide range of energies allows us to identify the different radial mode families.

IntroductionIII-N materials have become the dominant materials for UV to blue-green semiconductor light sources. Due to the increasing demand for lower-threshold and higher efficient laser devices at room temperature there is an interest on fabricating low-dimensional laser devices in order to reduce the non-radiative mechanisms taking place in bulk material especially at high temperature. Moreover by strongly coupling the emission with resonant modes of a micro-cavity strong Purcell effects can be observed increasing further the efficiency of the emitters.

Recent results have shown that GaN/AINQuantum Dots (QDs)with a high radiativeefficient can be grown on Si substrate [1]. The incorporation of dots to photonic resonators such as microdisks [2] can reduce the optical losses of the cavity due to lower absorption of dots compare to wells [3] with aim to fabricate novel type of lowthreshold laser devices without the requirement of systems with high optical gain [4][5].

In this work we report considerable improvement of the optical quality of microdisks with embedded GaN/AIN QDs. By performing micro-photoluminescence ( $\mu$-PL) measurements we observe high quality whispering gallery modes (WGMs) with high $\mathrm{Q}$ factors $(\mathrm{Q}=\lambda / \delta \lambda)$, i.e. up to 6000 for the $5 \mu \mathrm{m}$ in diameter microdisk, which is to our knowledge the best reported value for nitride based photonic cavities. Also, we present PL spectra for microdisks of various diameters at room temperature, showing a large number of spectrally uniform modes appearing within the whole spectrum. This allows identifying different families of resonant modes particularly in the case of $2 \mu \mathrm{m}$ microdisk.

Experimental The QD structureshown in figure 1(a) isgrownby (ammoniabased) molecular beam epitaxy. The GaNdotsaregrown on the top ofAlNbarrierandthe sample consists 4 periodsof 7ML/10nmGaN/AlNlayerswhicharegrown on a thin 35 nmAlNbufferlayer. The wholeopticallyactiveareaisverythin, i.e. 100 nmandisgrown on the top of a Silicon substrate. This area will serveas a single-mode waveguide in themicrodisk plane. The $\mathrm{Si}$ isselectivelyremoved in theareabelowthewaveguide in orderto form themicrodisk on the top of $\mathrm{Si}$ postasitisshownbytheScanning ElectronMicroscope (SEM) image (Figure 1b).The optimizationoftheetchingconditionsleadto smooth sidewallsofthemicrodisk, andisfurtherconfirmedbythe high measured $Q$ factors. Further detailsaboutthestructuregrowthandthemicrodiskprocessingstepscanbefoundelsewhere [1]. 


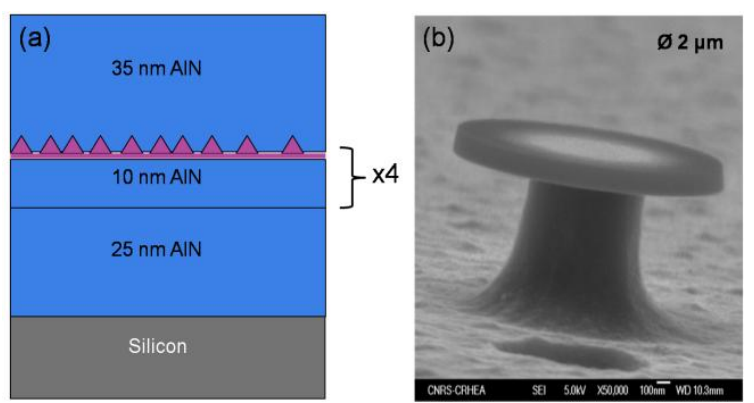

Figure 1 a) Epitaxial structure : the optically active area above the Silicon substrate contains 4 periods of GaN/AlN QDs layers. b) Scanning Electron Microscopy image of a $2 \mu \mathrm{m}$ in diameter microdisk.

Forthecharacterisationofthemicrodisksweperformed $\mu$-PL spectroscopymeasurementsbyphoto-exciting a singlemicrodiskwith a $266 \mathrm{~nm} \mathrm{CW}$ laser beam andbycollectingthe PL emissionfromtheedgeatthemicrodisk planeatroomtemperature. The PL signal was detectedby a cooledCCD camera after beingdispersedby a spectrometerhaving a high resolutionupto $\sim 0.16 \mathrm{meV}$.

Results and DiscussionFigure2showsthe PL spectrumof a $2 \mu$ mand $5 \mu \mathrm{m}$ in diametermicrodisks. The sharp peaks uniformly and periodically appearing across the spectrum correspond to WGMs which are distinguishable within a wide spectral range covering from $2.6 \mathrm{eV}$ to $3.5 \mathrm{eV}$. This interesting feature is due to the inhomogeneous broadening of dots PL emission, underlined by the broad background level peak of the PL spectra in figure 2, which can probe the microdisk resonant modes over a wide spectral range [3]. Such a uniformity of the WGMs across the whole spectrum as well as the fact that these modes are clearly distinguishable for a wide spectral range has not been observed in previous works on nitride based microdisk due to re-absorption of photons in the active area incorporating Quantum Wells (QWs) [3] [7].
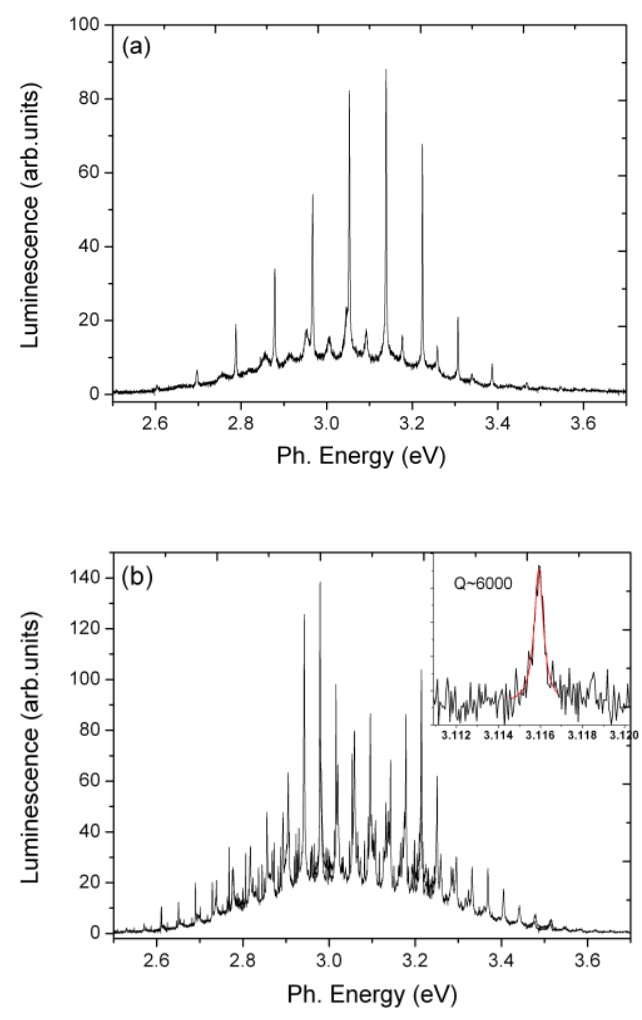

Figure 2 Photoluminescence spectra of a (a) $2 \mu \mathrm{m}$ and (b) $5 \mu \mathrm{m}$ in diameter microdisk. Inset : High resolution spectrum of a WGM of high $\mathrm{Q}$ value, i.e. $\mathrm{Q} \sim 6000$; the peak is fitted by a lorentzianlineshape (red line).

In the case of a $5 \mu$ mmicrodisk (figure 2.b) a high number of spectrally very close WGMs appears on the PL spectrum. By increasing the radius of the microdisk then the number of radial modes (given by $n$ ) and of azimuthal order modes (given by $\mathrm{m}$ ) are both increasing. Theoretically, lower radial and higher azimuthal order 
modes show higher $Q$ values [8]. Thus, here for the $5 \mu \mathrm{m}$ we obtained record $\mathrm{Q}$ values up to 6000 (see an example of high Q mode in the inset of figure 2(b)) compare to Q reaching a value up to 5000 for the $2 \mu \mathrm{m}$ microdisk. However the increase of the $\mathrm{Q}$ factor, as well as the fact that there is a greater number of modes propagating far from the highly absorbing Silicon post for a wider in diameter microdisk, is at the expense of coupling a single dot emitter with several very spectrally close modes. This is not desirable as it limits the coupling efficiency of the QD emitter with a single mode which is the requirement for observing strong Purcell effect [3].

Within the microdisk micro-cavities studied here the limitations of the WGM Q values are described by the equation [6]

$$
\mathrm{Q}=\mathrm{Q}_{\mathrm{rad}}^{-1}+\mathrm{Q}_{\mathrm{scat}}^{-1}+\mathrm{Q}_{\mathrm{abs}}^{-1}
$$

The two first factors $\mathrm{Q}_{\mathrm{rad}}{ }^{-1}$ and $\mathrm{Q}_{\text {scat }}{ }^{-1}$ are related with photons which radiate outside the cavity due to tunneling $\left(\mathrm{Q}_{\mathrm{rad}}{ }^{-1}\right)$ or to scattering by imperfections of the microdisk sidewall $\left(\mathrm{Q}_{\text {scat }}{ }^{-1}\right)$. The last factor depends on the absorption coefficient of materials in the waveguide [6]. For the sample described here the first two factors of equation $(1) \mathrm{Q}_{\mathrm{rad}}^{-1}$ and $\mathrm{Q}_{\text {scat }}^{-1}$, are estimated by the waveguide geometry and the roughness of the micro-disk sidewalls[8] respectively. Due to high quality of the etching and the strong confinement of the modes inside the microdisk, absorption is considered as the main mechanism responsible for optical losses. Absorption can take place either in the silicon post or in the nitride layers (barrier, wetting layer and QDs).

Figure 3 Different radial order families of WGMs for a $2 \mu \mathrm{m}$ microdisk as these are indicated (a) by the colored fitted lorentzian curves of the modes, i.e. red and green corresponding to lower and higher order modes respectively, and (b) by their Free Spectral Range (FSR) with respect to the whole PL spectrum.

In order to explore the different radial mode families appearing on the PL spectra we analyze the spectral spacing of the modes of the $2 \mu$ mmicrodisk (figure 3), named the Free Spectral range (FSR). Figure 3(a) presents two different families of modes along the PL spectrum, with an estimated Q value and a fitted Lorentzian curve. The FSR of these modes is plotted in (figure 3(b)). We can identify two different radial mode families from the spectral dependence of the FSR. Lower order modes (appearing with red color in figure 3) exhibit a smaller mode spacing and higher Q value than higher order modes (appearing with green color in figure 3) [8]. For the $1^{\text {st }}$ radial mode (i.e. the lowest-order mode) the FSR can be approximated as

$$
\Delta \lambda_{\mathrm{n}=1}=\lambda_{0}^{2} / \pi \mathrm{Rn}_{\mathrm{eff}}
$$

where $\lambda_{0}$ is the wavelength in vacuum, $\mathrm{R}$ the microdisk radius and $\mathrm{n}_{\mathrm{eff}}$ the effective refractive index of the 1D slab waveguide. At $3 \mathrm{eV}$, this worth $\Delta \lambda_{\mathrm{n}=1 \text { (theor) }} \sim 85 \mathrm{meV}$, in a very close agreement with the $\Delta \lambda_{\mathrm{n}=1(\text { (exp) }} \sim 86 \mathrm{meV}$. Thus, we associated the highest $\mathrm{Q}$ factor family of modes (red in figure 3) with the first radial order modes; the next family of modes (green) is attributed to the second radial order modes.

\section{Conclusions}

We have demonstrated high $Q$ values up to 6000 of resonant modes of microdisks embedding GaN/AIN. The wide spectral PL emission of QDs at room temperature allowed us to observe a high number of whispering gallery modes within a wide range of energy, i.e. from $2.5 \mathrm{eV}$ to $3 \mathrm{eV}$. Concerning the $2 \mu$ mmicrodisk, the FSR between modes allows identifying the two first families of radial modes.

AcknowledgementsThis workissupportedbythe French Agence Nationale de la Recherche (ANR) undertheresearchprogram SINPHONI ANR-08NANO-021-01.

\section{References}

[1] S. Sergent, J. C. Moreno, E. Frayssinet, S. Chenot, M. Leroux and F. Semond, Appl. Phys. Expr. 2, 051003 (2009).

[2] S.L. McCall, A.F.J. Levi, R.E. Slusher, S.J. Pearton and R.A. Logan, Appl. Phys. Lett. 60, 289 (1992).

[3] B. Gayral, J.M. Gérard, A. Lemaître, C. Dupuis, L. Manin and J.L. Pelouard, Appl. Phys. Lett. 75, 1908 (1999).

[4] F. Bordas, C. Seassal, E. Dupuy, P. Regreny, M. Gendry, P. Viktorovich M.J. Steel and A. Rahmani, Opt. Express 17, 5439 (2009).

[5] S. Strauf, K. Hennessy, M.T. Rakher, Y.-S. Choi, A. Badolato, L.C. Andreani, E.L Hu, P.M. Petroff and D. Bouwmeester, Phys. Rev. Lett. 96, 127404 (2006).

[6] R.E. Slusher, A.F.J Levi, U. Mohideen, S.L. McCall, S.J. Peatron, and R.A. Logan, Appl. Phys. Lett. 63, 1310 (1993).

[7] A.C Tampoli, E.D. Haberer, R. Sharma, K.H. Lee, S. Nakamura and E.L. Hu, Nat. Photonics 1, 81 (2007).

[8] M. Borselli, T.J. Johnson and O. Painter, Opt. Express 17, 5439 (2005). 